\title{
Influencing Factors and the Effect of Organizational Capabilities on Internationalization Strategies for German SMEs in the MedTech Industry
}

\author{
Gunther Heiss \\ University of Gloucestershire, Cheltenham, United Kingdom
}

\begin{abstract}
This paper is focusing on SME internationalization and investigates the antecedents and the effects of organizational capabilities on strategy in the German MedTech industry. However, the impact of existing research in this field is relatively poor and is not yet applicable in other countries or industries. As a consequence, a systematic review of the literature has been conducted. The results have shown heterogeneous research outcomes in the field of strategy and the need for further research in this context. Overall, the review indicates an initial conceptual model that has been developed, in which significant findings could be identified and refined in a country-, industry- or firm-specific way. The results will serve as a strategic input for SME’s in the German MedTech industry.
\end{abstract}

Keywords: internationalization, SMEs, MedTech, antecedents, organizational capabilities

\section{Introduction}

Germany is the third largest medical technology provider in the world. German small and medium sized enterprises (SMEs) enjoy universal recognition as manufacturers of medical technology (MedTech) products (MacDougall, 2012). They play an important role in their domestic market as veritable niche leaders. They are strong in domestic and EU markets, but compared to other high-tech industries most of them are under-represented in the large overseas markets and in the growth markets. But today healthcare market growth rates in Germany and the EU are stagnating due to restrictions on taxation and social security contributions, whereas foreign markets develop dynamically (Kuhlmann, 2014). Consequently, SMEs in this industry face a fundamental challenge. High product development costs with respect to a distinctive innovation strategy force companies to increase turnover and recover investments via internationalization, while this is constrained by financial and managerial resource limitations or challenging environmental factors such as regulations. There is a strong motivation for such SMEs to find a way to successfully internationalize their business - otherwise they might disappear from the market sooner or later. This would have an economic impact both on the industrial development in Germany and on the healthcare system (Wintermantel, 2009).

The aim of this research is to find out, which specific factors influence the strategic approach and consequently the development of international ventures in German MedTech SMEs, how organizational capabilities are related to their strategic approach and what influence they have on strategy execution. Based on

Gunther Heiss, Dipl.-Ing. Ph.D. candidate, University of Gloucestershire, Cheltenham, United Kingdom.

Correspondence concerning this article should be addressed to Gunther Heiss, Loogestieg 13, 20249 Hamburg, Germany. 
theoretical justification and on an empirical investigation, a conceptual model of international expansion in this industry leads to understand the behavior of such SMEs and evaluates important ingredients of success and identifies those that appear to be most prevalent.

\section{Research Questions and Gaps in Knowledge}

In strategy, development firms have different strategic options and internationalization can be an important element to support a firm's overall strategy. In the context of strategy, the internationalization process is complex and determined by many different factors that encourage or discourage international involvement. There is some disagreement within the literature in terms of the relative significance of internal versus external contingency factors. According to Murray, Gao, and Kotabe (2010) researchers have conceptualized the environment as one of the key constructs of understanding organizational behavior and strategic approach depending on the competitive setting of the business. In contrast, Leonidou and Katsikeas (2010) hold the view that internal organizational characteristics are more important, particularly in an organizational and managerial context. Nevertheless, the findings suggest, that whilst there are some common processes and patterns among firms' internationalization, the variations can be explained through the contingency theory. However, this neglects the specific industry context in which the firms operate as an important factor in their internationalization process.

According to Vignali (2003) the necessity of the development of a strategy and the need of proper execution cannot be questioned. Consistency of the elements and activities that refer to the strategy is a prerequisite of a company achieving success on the market. Nevertheless strategy development, implementation and execution of German SMEs vary over time. Some decades ago, with $11 \%$ only a minority of these SMEs agreed to have strategic planning. In recent years, meanwhile $54 \%$ of these companies came to a formal and written strategy paper, which they use as a guideline for their daily business decisions (Geyer \& Uriep, 2012). But different research studies show heterogeneous results related to the content and depth of the incorporated strategy elements and are therefore addressing the need of further research.

According to Morgan, Kaleka, and Katsikeas (2004) organizational capabilities affect the development and execution of firm's internationalization strategy and therefore its performance. Through the lens of the resource-based view capabilities, a firm's management skills or its organizational processes for instance, are valuable and rare (Barney, 1991). Following the knowledge-based theory, a firm's capability to co-ordinate internal competencies enables the transformation of knowledge into value creating processes (Dosi \& Marengo, 1994). But there is a discourse on the impact of capabilities on strategy and a firm's success. Atuahene-Gima and Murray (2004) highlight the influence of organizational capabilities in the context of the strategy development. In contrast, Lages, Silva, and Styles (2009) see little empirical evidence of strategic impact of capabilities on strategy and performance in the context of internationalization. Hence Theodosiou and Katsikeas (2013) consider firm's capabilities as a specific field of interest for future research. Following the resource-based view, the size of a firm plays an important role with respect to SMEs internationalization process and Shaw and Darroch (2004) observe a notable gap in the literature, particularly concerning the role of organizational capabilities for SMEs.

That's the reason why the research investigates which specific factors influence the strategic approach to international ventures of in the MedTech industry. Furthermore, it intends to find out about the impact of strategy development on the internationalization of German MedTech SMEs and how do organizational capabilities affect the internationalization strategy execution of German SMEs in the MedTech industry. 


\section{Research Context and the Relevance of Research}

This research context was chosen for several reasons. First, the MedTech industry is an important industry sector of the German national economy. Furthermore it is mainly based on SMEs, which drive innovation and facilitate competition. The size of a firm plays an important role particularly in the context of limited resources and knowledge. Organizational capabilities are crucial to develop singular managerial experience and skills of foreign markets and business practices into organizational knowledge. Shaw and Darroch (2004) observe that particularly SMEs are severely affected by this fact in their internationalization process. Mathews (2002) describes this lack of knowledge regarding SMEs as a barrier; he further identifies that relationship capabilities play an important role for SMEs, since they drive the development of market relationship and consequently firm's collaboration network. Second, although some internationalization theories are based on surveys in the heatltcare sector, not all aspects of the current development are theoretically covered. Recent research in the context of the MedTech industry emphasizes industry-specific factors. According to Chatterji (2009) the economic success is e.g. more driven by regulatory knowledge than by technology or product-know how. Only a few MedTech SMEs have managed to internationalize their business against global NMEs and local competition in the oversea markets.

Hence, there is a lack of specific predictions for the future development for this industry sector and related managerial implications. But it is important for the Healthcare-System that excellent healthcare services based on innovation and competition by SMEs can be provided also in the future.

\section{Research Background}

\section{MedTech SMEs in Germany}

SMEs play an important role regarding the GNP or employment rate and are therefore called the "backbone" of the German industry (IFM, 2012). Today, Germany is one of the leading export nations along with the SMEs that are predominantly positioned and supporting the current economic development (Geyer \& Uriep, 2012). Most German SMEs have international business and 69\% of the companies have export business, but only $15 \%$ use representatives and less than $5 \%$ cooperate or have own subsidiaries in foreign countries (Geyer \& Uriep, 2012). For the future, it will become even more crucial for SMEs to intensify their international engagement (BDI, 2011). The health care industry incorporates several sectors that are dedicated to providing health care services and products. According to the industry and its own market classifications, health care includes many categories of medical equipment, instruments and services as well as biotechnology, diagnostic laboratories and substances, as well as drug manufacturing and delivery. Medical equipment is used in nearly all medical applications and medical technology products can be found in all stages of human life to support the health of human beings. Not at least with the help of highly innovative medical devices, the possibilities in diagnosis, therapy and care have been developed significantly in the last decades, which consequently enable the positive development of public health in many countries all over the world. Today's products that are available in this market include a wide range from high-end products, e.g. for diagnostics, therapy, and monitoring, to commodities suitable to more general health care provision (MacDougall, 2012). Medical devices designed and produced by German SMEs assist us during our whole lifetime. Ultrasonic tests help in diagnoses during pregnancy, incubators support therapy in preterm birth, orthopedic or ophthalmological devices correct deficiencies, devices for emergency care are crucial in case of accidents to 
save lives and implants such as pace makers or artificial hips at an older age.

As a result of significant demographic and technological developments, the world market for medical technologies currently totals in the region of more than EUR 200 billion per year-a figure that is increasing all the time (Kuhlmann, 2014). As such, Germany is the third largest medical technology provider of products and medical services in the world (IFM, 2012). In terms of new patent registrations, German manufacturers are positioned second after the USA, making Germany Europe's strongest region for innovation in this industry. The medical technology producers in Germany achieve approximately one third of their turnover with products that are less than three years old. More than two-third of the generated revenue in this industry belongs to SMEs (MacDougall, 2012). Companies, technological products, markets and public authorities are some of the parameters that can be found in the described field of management research within German medical technology industry. It can be characterized as a high-tech sector with high levels of innovation and a strong export orientation. Around $15 \%$ of all employees in this industry work in R\&D, highlighting the significant importance that Germany assigns to R\&D and innovation in the medical industry (MacDougall, 2012).

The governmental German trade and invest agency highlights the medium-sized company oriented structure with niche products for specialist application as unique characteristic of German medical technology. Ninety-seven percent of all medical technology firms in Germany employ less than 500 employees. These SMEs with less than 500 employees account for roughly $40 \%$ of the total turnover and more than 1,200 companies are active in this medical technology sector (Kuhlmann, 2014). German companies servicing this market represent a turnover in total of 21.4 billion EUR in 2011. German medical technology export shares in target regions concentrate on the EU with $40 \%$ (increase versus previous year $+6 \%$ ), followed by North America with 20\% (+13\%), Asia with 17\% (+26\%) and remaining 33\% belong to the rest of the world. The US is the largest national market followed by Japan and China, whereas German MedTech SMEs often focus on the nearby EU countries (Kuhlmann, 2014). Only few of them have managed to internationalize their business against global NMEs and local competition in the oversea markets.

\section{Regulations in the Medical Device Industry}

However, compared to other industries (e.g. the consumer industry), the MedTech industry is depending on enormous local regulations and authorities. The European medical device directive or the Food and Drug Administration (FDA) in the US are examples of strong regulatory foundations, which have to be respected when operation in these healthcare-markets. These regulations differ significantly from country to country along with the lack of harmonization in legal provisions for international standards of regulations. Consequently, the investments for certifications-a prerequisite for entering the market-are significantly increasing (Kramer, 2012). The low level of worldwide harmonization of regulations in the medical business has an influence on many fields of activities across nearly all processes of a medical device manufacturer. This means that special requirements are needed compared to other industries e.g. in the product design phase in order to meet the product safety requirements. Different countries have different regulations according to the set-up the quality management system, the vigilance system, the classification of products with respect to applications or for the procedure of approval and certifications (Bijayata, 2012).

Regulations, which force to reveal technical details in documents and tests, can create tensions with different impacts on SNEs and MNEs in the context of technical know-how and risk. Knowledge prevention 
and related perceived risk can also play a role for innovation driven SMEs when considering internationalization strategy. With respect to marketing strategies, this often means delays for meeting the timeto-market announcements followed by additional market entrance costs and permanent expenses to run the organization in compliance according to the different national standards (Herok, 2009). Following the resource-based view, it is much more difficult for SMEs in the MedTech sector to expand and internationalize their business compared to NMEs or the global players in this market. Maintaining the structures and achieving the necessary certificates and approvals required to serve a specific market worldwide, could be a real challenge (Emninet, 2010).

\section{Literature Review}

\section{Literature Review Design}

Conducting a literature review is a means of gaining insight into a particular field of study, including theories, main contributors, key variables, methods, and history (Randolph, 2009). The literature review also helps to distinguish what research topics already have been visited and what has been addressed for future research. As suggested by Tranfield, Denyer, and Smart (2003) for management research prior to the beginning of a review, a scoping study was conducted to assess the sizes of the literature in the field and to delimit the subject area by finding studies of different subject areas. This led to deeper information about the quantity of scholar articles regarding key terms in the title of this review and provided a better landscape of frequently used sources. The coping study was conducted in different stages based on an Internet search with specific combinations of search terms such as SMEs, Strategy, Healthcare, Medical Technology, and Regulations. Starting point was the effective use of advanced searches by specific attributes and their combination with the help of Boolean terms in different databases. According to the research objective the review contained the terms SMEs (in German industry), (Business-) Strategy, Healthcare (market), Medical Tech (companies) and regulation (relevant to the medical device industry) within their complementary context. Due to the vast amount of empirical research in this field of research, 10 possible combinations within the scoping review have been applied. Furthermore, 10 thesis and dissertations have been analyzed according to the specific search terms.

Finally 40 studies, articles and research papers passed the gate to the step synthesis. In the next step, a qualitative synthesis of the empirical articles that met these criteria has been developed by comparing and contrasting the results of the individual studies, generating categories and core concepts. Consequently, the final result of this step is a table, containing the common synthesized concepts and results from all articles reviewed in the process of this literature review. In a next step, sources and databases have been evaluated by a peer review. Additional journals have been selected as valuable sources. As a result, a manual search of research articles in the last 10 years in the Journal of International Marketing and in the Journal of Academy of Management Journal has been performed and the results were added.

Based on the entire outcome that is referring to the identified constructs and synthesized concepts, a conceptual framework was developed in several steps in parallel with the literature review. The results of the new research and literature-net based in-depth surveys helped finally to sharpen und refine the overall framework that is illustrated at the end of the chapter.

\section{Basic Theories and International Strategies}


Internationalization from a company perspective can be described as the process of becoming multinational. In the first phase of this process, a company sells its products in the domestic market. In a second phase, the company begins selling its products abroad. The next step in the internationalization process may be the establishment of an international sales network. Then the process of internationalization has advanced so far, that the individual company has manufacturing, sales and R\&D in a number of countries and becomes multinational (Levitt, 1983). Many of the selected studies and articles refer to a functional model based on Porters five forces model (Porter, 1980). But also other established constructs such as Dunning's (2000) OLI Model or Johansen and Vahlne's (1990) Uppsala Stage Approach are often named theories in the context of internationalization strategies. Based on the generic orientation of strategy (Porter, 1986), firms have different strategic options and internationalization can be an important element to support a firm's overall strategy.

Theoretical frameworks related to internationalization often draw to one of the three main strands of the literature, namely the stage theory, contingency theory(ies) and the resource-based view. The different internationalization approaches recognize the multiple influences on the internationalization process and are linked to different fields of research such as export behavior, international marketing, marketing and resource-based literature etc.

Although export is only one characteristic of firm's internationalization, it can be understood that various factors influence the strategic decision-making and execution. A review concerning research articles in the context of export business (Leonidou \& Katsikeas, 2010) shows the various facets of this subject matter. The subject of overall export strategy was most often examined in conjunction with antecedents (e.g., environmental, firm, or product) and/or outcomes (e.g., export performance) of marketing strategy standardization or adaptation. But also export products in the context of standardization versus adaptation were a dominant topic, followed by branding strategy and new product development, export pricing/financing and export distribution/logistics have traditionally been an attractive subject for many export researchers.

\section{Critical Reflection on International Strategies}

Internationalization as strategy process within the international business research may be blurred by the multidiscipline nature of the field such as the stage models of Internationalization, SMEs' deficiencies regards strategy or structure and administrative processes. It can be questioned whether these patterns and models still fit in general. Circumstances have changed over time and internationalization theories do not cover all aspects of the current development and transformation in the world (Holtbrügge, 2005). For instance, transportation has become cheap and information technology as well as digital business models which enable a close cooperation all over the world. The availability of critical knowledge in the digital age, where real-time information is available at any place in the world, might be an essential enabler for recent developments. But also might cause a change for already established business paradigms.

Therefore it is not surprising that the theoretical framework of internationalization theories is going to be continuously enhanced and it seems that SME specific aspects are more and more integrated. One example is Mathew's (2011) LLL model, which describes the lack of knowledge of SMEs but also the possibility and consequently the importance on the development of leveraging their capabilities. Johanson and Vahlne's (2009) "Liability of Outsidership" approach is focusing on these collaboration aspects due to the fact that networks and collaboration drive relationships and hence facilitate business networks, which are elementary for business success. Further, the established internationalization Uppsala Stage Theory has been revisited. The knowledge 
creation has been added to recognize the fact that new knowledge is developped in relationships. Finally, according to Dunning and Lundan (2008), the "OLI" approach has been extended with respect to strategic alliances. But this cannot cover the whole range of phenomena related to SMEs' internationalization. Other modern empirical findings demonstrate that SME internationalization modes are not path dependent, emergent or incremental (Schulz et al., 2007).

\section{Influencing Factors}

It is obvious that the process of strategic decision-making and strategy execution is determined by many different factors. Some scholars group them into classes such as external environment, internal environment, and product-market structure. The contingency theory recognizes the importance of external environmental factors of firm's strategy that affect organizational actions. Leonidou (2010) is focusing on environmental and internal factors, particularly in an organizational and managerial context. This means that internal factors such as capabilities also affect the firm's internationalization strategy (Morgan et al., 2004). Following the knowledge-based theory, a firm's capability to manage internal competencies enables the transformation of knowledge into value creating processes (Dosi \& Marengo, 1994) and, particularly the organizational capabilities influence the strategy development (Atuahene-Gima \& Murray, 2004).

According to Theodosiou and Katsikea (2006), the strategic fit of a marketing strategy and its influence on the performance outcome is influenced by three macro-environmental factors (regulatory environment, technological intensity and velocity, customs and traditions) and three micro-environmental forces (customer characteristics, product life cycle stage, competitive intensity). Some scholars distinguish between endogenous or exogenous factors; others recognize them as positive triggers that encourage international involvement, or negative barriers that discourage it. Psychological distance is often named as barrier. The perception of barriers differs between NMEs and SMEs. Scholars agree that foreign country-related topics like risks and hazards have more influence on SMEs' decisions. Particularly the safeguard know-how characterizes a main difference whereas criteria like transaction cost seem to work on both SME and MNE.

There is some disagreement within the literature in terms of the relative significance of internal versus external contingency factors. The extant literature emphasizes the significance of external triggers, such as the market structure and its dynamics. According to Murray (2010), researchers have conceptualized the environment as one of the key constructs of understanding organizational behaviour and the strategic approach depending on the competitive setting of the business. In contrast, Leonidou (2010) holds the view that internal organizational characteristics are more important, particularly in an organizational and managerial context. As result of a qualitative synthesis, based on the findings from the reviewed articles, three different categories of influencing factors can be distinguished. Although the definition which specific variables represent the different categories in this framework will be described later, it can be recognized that a perspective with respect to product, firm, and environment related factors could group most of the factors extracted from the literature review.

\section{Strategy Approach}

Literature about strategy covers a broad field of subject matters. In management research, strategy related to economics was developed at Harvard Business School in the 1950s. According to the comprehensive approach, which is chosen in the context of this review, strategy can be understood as a seamless merger of all activities of a company (Porter, 1986). According to Whittingtion (2001), different perspectives of strategy can 
be found in research with a different focus over the last decades. Chandler's (1962) "Structure follows Strategy" approach illustrates a functional perspective, which shows that there is a relationship between organization, structure, and strategy. According to Murray (2010), there is a need to develop a level of strategy fit that is consistent with organizational resources in order to determine a firm's success.

The necessity of the development of a strategy and the appropriate tactics for the achievement of that strategy is widely agreed. The task on how to bridge strategy and tactics needs to be thought out during the process of strategic planning. According to Vignali (2003), this process is wise to view as somewhat separate and related to the strategic level of management. Looking through the lens of the resource-based view, this construct of strategy development and strategy execution has brought special attention for SMEs as well in the context of this research. A subset of strategy is strategic planning. Strategic planning is influenced within a company by a range of factors, e.g. its culture, leadership, size, ownership, perceived market share, and industrial sector. Wirtschaftslexikon (2012) according to the literature, there seems to be significant differences in the development of a strategy and decision-making processes between global players and SMEs (Martin, 2005). Based on the experience of the author, this is also true within the segment of healthcare and different MedTech companies according to the development of their business strategies. The strategic decision management in SMEs follows different stages (Wheelen \& Hunger, 2006). A product and environmental scan related to risk and opportunities is followed by an organizational analysis with respect to strength and weakness of internal factors. As a consequence of these results, a firm specific strategy can be formulated.

Finally, the construct of formal strategy development and execution, which is influenced by various factors explained before, has its firm specific characteristic regards meaning, strategic elements, or tactical implementation. Consequently, the strategic approach seems to be moderated by other variables, summarized under organizational capabilities and described next.

\section{Capabilities}

Through the lens of the resource-based view, capabilities are valuable and rare. They can be viewed as bundles of tangible and intangible assets, including a firm's management skills, its organizational processes and routines, the information and knowledge it controls (Barney et al., 2001). Following the knowledge-based theory, intangible assets such as knowledge and firm's capability that are essential to manage internal competencies, enable the transformation of knowledge into value creating processes (Dosi, 1994). There is a current discourse in research on the impact of capabilities on strategy and firm's success.

Strategy capabilities, meaning the strategic fit of firm's strategy according to resources both in development and execution, are seen as an antecedent for competitive advantage and economic success. Organizational capabilities may have an influence on the relationships of this construct and therefore internal organizational capabilities such as organizational learning; coordination mechanisms and relationship capabilities are of particular interest. Also a firm size plays an important role particularly in the context of limited resources and knowledge. Organizational learning capabilities are crucial to develop singular managerial experiences and skills of foreign markets as well as converting business practices into organizational knowledge. Following the resource-based view, Shaw and Darroch (2004) see particularly SMEs severely affected in their internationalization process by the lack of capabilities. Once the requested information is available and knowledge is available, further organizational capabilities are needed to span people together in order to enable distinctive activities, which contribute to firm's success by deploying 
organizational routines and processes. Therefore coordination mechanisms are seen as a valuable capability. Relationship capabilities are also important as recent literature highlights the magnitude of networks and collaboration as essential factors for SMEs, since they drive the development of market relationship and consequently firm's business network.

Finally, these different capabilities can be combined in a second order construct named organizational capabilities, which are supposed to have a moderating effect on both, the strategic and the tactical level of firm's internationalization and thus on its international ventures.

\section{Competitive Advantage and Economic Success}

Studies referring to firm's international performance and economic success employed a wide variety of export performance measures, are ranging from economic (e.g., export sales ratio, export profitability, export market share) to non-economic indicators (e.g., new products exported, export market penetration, and number of export ventures). According to Cavusgil, Tamer, and Zou (1994) the economic success of export ventures, which are defined as a single product or product line exported to a single export market, can be measured more precisely than periodically added margins related to a product-portfolio.

According to Leonidou and Katsikeas (2010), who examined research articles over the past decades, export performance was the one of the most researched topics. This is attributable to the fact that export performance is the end result of the firm's marketing efforts and other business activities in foreign markets, providing an indication of its overall success or failure and determining further continuation of or withdrawal from exporting. Since the export performance is influenced by various factors, a number of different associations have been investigated such as the export performance related to marketing strategy or the various background variables such as firm size, quality, or relationships with foreign customers.

Some scholars emphasize distinctive key factors in the context of economical success and foreign business. Lages et al. (2009) focus their research on quality and innovation as determinants of export performance. Leonidou (2010) sees the relationship of export performance and product quality as important but widely researched whereas the relationship of export performance and product innovation is seen as rarely investigated. However, technical innovation is also identified as a strategic key factor (Souitaris, 2001). This is relevant in this research context since MedTech companies in Germany achieve approximately one third of their turnover with products that are less than three years old (Wintermantel, 2009).

Leonidou and Theodosiou (2011) highlight that the adoption of specific national export-promotion programs positively strengthen the firm's export-related resources and capabilities, which are instrumental in developing a sound export marketing strategy, and achieving competitive advantage, and in turn help to achieve superior export performance. National export-promotion programs can be seen as drivers of organizational resources and capabilities with effects on strategy, competitive advantage, and performance. Theodosiou and Katsikeas (2013) have centered their research on other key variables like environmental, organizational, and managerial factors as well as export marketing strategies, export marketing capabilities, and export competitive advantage, which have a significant impact on export performance (e.g., Cavusgil, Tamer, \& Zou, 1994; Katsikeas, Leonidou, \& Morgan, 2000; Morgan, Kaleka, \& Katsikeas, 2004; Morgan, Katsikeas, \& Vorhies, 2012; Murray et al. 2010). Barney (2009) highlights firm resources that are leading to sustainable competitive advantage by focusing on internal resources like physical, human, and organizational capital. Katsikeas (2012) sees the superior export performance linked to competitive advantages for specific competences and 
capabilities. These capabilities comprise: organizational learning, relationship capabilities and quality capabilities. This means that specific organizational capabilities are related to the execution of a certain strategy in order to ensure successful international business.

However, a chain of effects is related to international ventures with the aim to achieve competitive advantage, which is leading to economical success. As a summary, some factors have direct or indirect influence on the economical success of international ventures. Some of these factors are important in a general context while other factors have a specific weight in the context of SMEs or the MedTech sector. Hence this will be respected in the next section when specific variables representing the constructs in the chosen research context will be investigated in much more detail.

\section{Research Context Specific Factors}

This research focuses on SMEs in the MedTech industry in Germany. Hence the word "specific" here is related towards the firm size, the industry sector, and firms' country of origin. The following section has the objective to confirm - as far as this was not done in the previous sections-that the more general findings or concepts from the literature are also applicable in this specific context. There is also the intention to make further contributions on a more detailed level in order to select distinguished factors and variables, which represent the constructs in the specific research context in a best way. The following findings will start with general SME related findings, then the focus on SMEs in the MedTech industry will be added and finally country specific factors of such companies are reflected. It is intended, that the section should be a rationale and a starting point for assembling an initial framework based on the introduced constructs and relationships drawn from the literature.

Through the lens of the resource-based view, the firm size plays an important role. This is supported by various research articles, which refer to the statement "An SME is not just a small big firm” while addressing that SMEs have specific characteristics. Although firms' internationalization is based on established theories, specific internal and external factors play an important role for SMEs in this context. According to the knowledge-based theory, internal factors such as organizational capabilities enable firm's internationalization strategy by facilitating the transformation of knowledge into value creating processes. Recent research describes e.g. the lack of knowledge of SMEs and the importance of leveraging their capabilities, on relationships and business networks. Most SMEs have international business. Sixty-nine percent of the companies have export business but only $15 \%$ use representatives and less than $5 \%$ cooperate or have own subsidiaries in foreign countries ( Geyer \& Uriep, 2012).

This might be associated with the results of a study conducted by the German Chamber of Commerce. Based on several hundreds of answers in this survey, management resources, lack of experience and financial resources were identified as main barriers. More than two-third of the generated revenue in Germany's MedTech industry belongs to small and medium sized enterprises (Kuhlmann, 2011) and, as outlined by recent research, networks and collaboration are a way to compensate the lack of knowledge and capabilities, which often characterize the situation in SMEs' business. As a result, the second order construct of organizational capabilities, which has been shaped and detailed by introducing three specific organizational capabilities related to learning, relationship, and coordination mechanism as representatives, can be confirmed in the specific research context.

From another perspective, Julien (2003) identified in a literature review 16 competitive factors that small 
firms use. The majority of them refer to product strategy (such as scope, differentiation, technology etc.). Namiki (1988) empirically shows that SMEs use four types of competitive strategy. An approach reflecting an innovation position and niche operation has a positive effect on firm's internationalization and profitability (Qian \& Lee, 2003). SMEs' performance is likely to improve as they increase the degree of formal planning routines adopted from MNEs with respect to strategy and innovation (Terziovski, 2010). Product development leading to innovation supports also the successful internationalization approach of MedTech SMEs (Hourd \& Williams, 2008).

More evidence of country specific behaviors of Japanese, British, US, and German MedTech SMEs can be found in a study, which compares different export strategies (Williamson, 1990). British companies were dominated by UK supply and demand considerations, Japanese companies invested heavily in distribution and support channels, whereas German companies have built their shares on technological advantage and direct sales. Although the study is some years old, German MedTech enterprises still have a strong approach towards technological leadership. In terms of new patent registrations, German manufacturers are positioned second after the USA, making Germany Europe’s strongest region for innovation in this industry (MacDougall, 2012). The results revealed the heterogeneity of MedTech companies and the distinctive features of the German MedTech SMEs regarding innovation process. Therefore the second order construct named "market specific product potential” represents product related factors such as product competitiveness, product innovation, and product quality. Products are the bases for international ventures and their characteristics have high impact on firm's strategy in this research context.

Although competitive products and services are the base for international ventures, they have always to be considered in the context of the specific situation with respect to market and competition (Theodosiou \& Katsikeas, 2006). But also external industry specific factors have a strong impact. The importance of regulations in healthcare has already been mentioned. Chatterji (2009) highlights that specific environmental factors such as regulations and approvals in the medical markets and the related know-how have a huge impact on the economic success of foreign ventures of SMEs in this industry. Hence specific environmental factors such as competition by MNEs or upcoming domestic firms in a foreign market, as well as market potential and medical regulations have a major impact on firm's strategy.

A survey in the MedTech industry focusing on SMEs in the UK gathered interesting results regarding motivation, barriers and success factors in the context of internationalization (Barnes et al., 2007). Higher market size, guard own resources by entering more markets and greater profit were named as motivation, whereas finding the right partner, local competition and limited financial and management resources were named as barriers. As success factors were identified e.g. product quality and competitiveness as well as an experienced management.

These findings support the already mentioned factors focusing on internal resources like physical capital, human capital, and organizational capital, and highlight some additional internal factors, which have influence on the strategy on the internationalization of MedTech SMEs. Often they have fewer skills and resources (Leonidou \& Theodosiou, 2011), which is an obstacle in the internationalization process since experience and management skills are seen as important resources. This is in alignment with Theodosiou and Katsikeas (2013) and Piakowski (2012), who see managerial factors as crucial in this context. According to the resource-based view financial and human resources are limited. But also information can be seen as critical resource (Souchon \& Diamantopoulos, 2003; Leonidas \& Theodosiou, 2011). The role of information acquisition, dissemination, 
and utilization is also confirmed by Theodosiou and Katsikeas (2013), who see information as an antecedent to support the full range of strategic and tactical decisions that are needed with respect to entering and penetrating a foreign market.

Hence the decision on grouping the factors in product, external and internal related categories reflected by second-line constructs can be confirmed. As outlined before, a product's competitiveness, innovation, and quality are the base of international ventures and form a firm's strategy, but influences also the market potential as well as the competitive position of a firm's strategy as external factors in general. Regulations are another important external factor in the MedTech business. Information and knowledge, a firm's resources with respect to human and financial capital have been identified as internal factors as well as management skills and experience, which are recognized in the SME context as important representatives of the second-line constructs influencing firm's strategy approach.

\section{Results From the Literature Review}

It has been elaborated, that SMEs in the medical device industry have to manage several specific challenges in adopting the right strategy for the future once they are willing to defend their position or to survive on the long range. While they have to foster continuous innovation and speed in a constantly changing market environment, they have to follow cost and often time-consuming regulation and approval procedures. The lack of know-how and resources can be limited by certain approaches, but not eliminated. Often they face the problem of finding the right partner to sell and service their products and on the other hand to prevent their know-how, which both have an influence on the internationalization strategy. Consequently it became apparent that some theories, constructs, and factors might be more applicable than others in the specific context of German MedTech SMEs. Thus, the findings from the literature review related to internationalization theories have been synthesized with the results, which have been elaborated with respect to the specific context of German SMEs in the MedTech industry.

As a result, a conceptual framework is derived from the literature review. The components of the theoretical framework drawing on the contingency literature and the resource-based view are intended to describe the mechanism of identified constructs and influencing factors on strategy development and execution of SME's internationalization. According to the findings highlighted above, the role of capabilities on international ventures is also considered.

The conceptual framework considers the strategy development and execution, named strategy approach of SMEs' internationalization. Based on the literature review, the construct of strategy approach is driven by specific factors. It has been elaborated so far that different internal and external factors play a role in firm's internationalization strategy. Factors such as competition and regulations play a specific role when competitive advantage is based on an innovation strategy particular in the context of internationalization of SMEs in strongly regulated industries. Firm's specific resources and products furthermore influence as the conceptual elements their strategy approach. The strategic approach is important for achieving competitive advantage and economic success and consequently for creating value for the company and its stakeholders.

Organizational capabilities have impact on firm's strategy, since steering capabilities are necessary to transform knowledge into value creation and networking, and collaboration helps to overcome the lack of knowledge, resources and capabilities. These dedicated organizational capabilities moderate the relationship of strategy approach and competitive advantage in international ventures. 


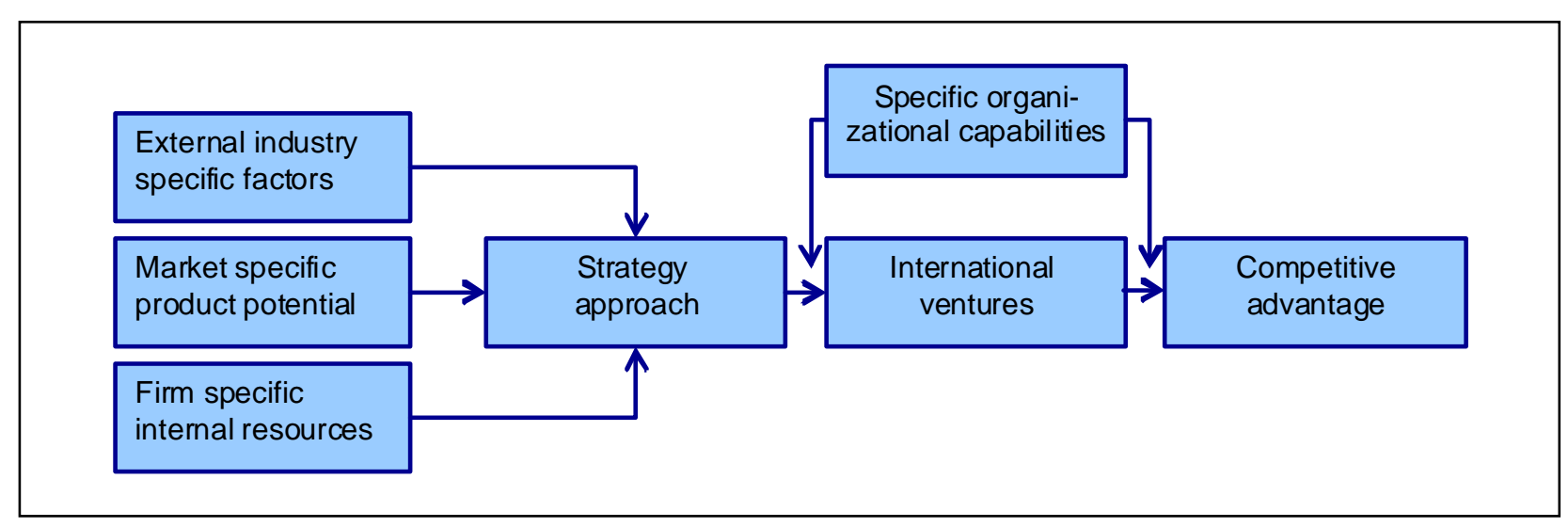

Figure 1. Conceptual framework.

\section{Conclusion}

The results are interesting for different groups: The academic community, the industry, and the governmental institutions with focus on export or foreign direct investments e.g. with respect to national export promotion programs related to industry specific topics such as medical device regulations.

From a theoretical point of view, this research is aimed to gather a deeper understanding regarding the behavior of SMEs in international ventures in a specific industry sector. The findings will help and contribute to evaluate the impact of organizational capabilities. From the perspective of the industry, this research will provide a scientific approach to the practical question of why some firms are more successful than others. This research will provide new insights with respect to the factors that practitioners must consider when attempting internationalizing their business within this industry.

Second, the knowledge of which factors have the strongest influence on strategy decisions, will help the industry to derive managerial implications from the study that business support providers can use to meet international customer needs and assist firms operating within this sector.

It is obvious that a profound understanding of the constructs and relations which have an impact on the internationalization of MedTech SMEs in Germany can be used by business support providers and governmental sources to support and assist firms operating within this sector e.g. by national programs or individual consult.

Nevertheless, there is still the need for further investigation in the context of specific influencing factors on strategy development, which should be considered in an empirical research design.

\section{References}

Ansoff, H. J. (1965). Corporate strategy. US: McGraw-Hill Inc.

Atuahene-Gima, K., \& Murray, J. Y. (2004). Antecedents and outcomes of marketing strategy comprehensiveness. Journal of Marketing, 68, 33-46.

Barnes, B., Chakrabarti, R., \& Palihawadana, D. (2007). Investigating the export marketing activity of SMEs operating in international healthcare markets. Journal of Medical Marketing.

Barney, J. B. (1991). Firm resources and sustained competitive advantage. Journal of Management, 17(1), 99-120.

Barney, J. B., \& Zajac, E. J. (1994). Competitive organizational Behavior. Strategic Management Journal, 15(31), 3-9.

Barney, J., Wrigh, M., \& Ketchen, J. D. (2001). The resource based view of a firm: Ten years after 1991. Journal of Management, 27(6), 625-641. 
Bijayata, U. (2012). Journal of Medical Device Regulation. Vol. August 2012.

BDI. (2011). BDI the Voice of the German Industry, the largest family-owned enterprises in Germany—Data, facts, potentials. Institut für Mittelstandsforschung, Bonn, Germany.

Cavusgil, T. S., \& Zou, S. M. (1994) Marketing strategy-performance relationship: An investigation of the empirical link in export market ventures. Journal of Marketing, 58(1), 1-21.

Chandler, A. D. Jr. (1962). Strategy and structure, chapters in the history of the American industrial enterprise. Cambridge: MIT Press.

Chatterji, A. K. (2009). Spawned with a silver spoon? Entrepreneurial performance and innovation in the medical device industry. Strategic Management Journal, 30(2), 185-206.

Dunning, J. H. (2000). The eclectic paradigm as an envelope for economic and business theories of MNE activity. International Business Review, 9(2), 163-190.

Dosi, G., \& Marengo, L. (1994). Some elements of an evolutionary theory of organizational competences, in evolutionary concepts in contemporary economics. Richard W. Englander (Ed.). Ann Arbor MI: University of Michigan Press.

Dosi, G., Nelson, R. R., \& Winter, S. G. (2007). The nature and dynamics of organizational capabilities. Munich: Oxford Press.

Dunnning, J. H., \& Lundan, S. M. (2008). Multinational enterprises and the global economy. Cheltenham UK: Edward Elgar Publishing Limited.

Emninet, Generics in small markets or for low volume medicines. The European Commission, 12/2010.

Federal Statistical Office (Statistisches Bundesamt): Small and Medium Enterprises (SME), SME's. http://www.destatis.de/jetspeed/portal/cms/Sites/destatis/Inter

Geyer, G., \& Uriep, A. (2012). Internationalisation strategies for SME’s. HWWI Policy Paper, No. 65, http://hdl.handle.net/10419/58267

Hawawini, G., Subramanian, V., \& Verdin, P. (2003). Is performance driven by industry-or firm-specific factors? A new look at the evidence. Strategic Management Journal, 24(1), 1-16.

Herok, C. (2009). Innovation and/or contra medical devices? Round Table Medizintechnik.

Holtbrügge, D. (2005). Working paper. The learning theory of internationalization by Johansson/Vahlne: Grundzüge, empirische Relevanz und Kritik, University of Erlangen-Nuremberg, Department for International Management.

Hoskisson, R. E., Wan, W. P., Yiu, D., \& Hitt, M. A. (1999). Theory and research in strategic management: Swings of a pendulum. Journal of Management: Official Journal of the Southern Management Association, 25(3), 417-456.

Hourd, W. (2008). Proceedings of the institution of mechanical engineers, part H. Journal of Engineering in Medicine, 222, 5717-5735.

IFM. (2012). World economic outlook databases. Washington. http://www-ifm-bonn.org/index.php?id=84

Johanson, J., \& Vahlne, J. (1990). The mechanism of internationalization. International Marketing Review, 7(4), 11-24.

Johanson, J., \& Vahlne, J. E. (2009). The Uppsala internationalization process model revisited: From liability of foreignness to liability of outsidership. Journal of International Business Studies, 40(9), 1411-1431.

Johnson, R. B., Onwuegbuzie, A. J., \& Turner, L. (2007). Toward a definition of mixed methods research. Journal of Mixed Methods Research, 1(2), 112-133.

Julien, P.-A., \& Ramangalahy, C. (2003). Competitive strategy and performance of exporting SMEs. Entrepreneurship Theory and Practice, Baylor University.

Kramer, D. B., Xu, S., \& Kesselheim, A. S. (2012). How does medical device regulation perform in the United States and the european union? A systematic review. Plos Medicine, 9(7), e1001276.

Kuhlmann, M. (2014). SPECTARIS German Industry Association for the high-tech medium-sized business sector and representative body in the areas of medical technology, optical technologies and analytical, biological, laboratory, and ophthalmic devices.

Lages, F. P., Silva, G., \& Styles, C. (2009). Relationship capabilities, quality and innovation as determinants of export performance. Journal of International Marketing, 17(4), 47-70.

Leonidou, C. L., \& Katsikeas, C. S. (2010). Integrative assessment of exporting research articles in business journals during the period 1960-2007. Journal of Business Research, 63, 879-887.

Leonidou, C. L., Palihawadan, P., \& Theodsiou, M. (2011). National export-promotion programs as drivers of organizational resources. Journal of International Marketing, 19(2), 1-29.

Levitt, T. (1983). The globalization of markets. Harvard Business Review, 61(3), 92-102.

Mathews, J. A. (2011). Competitive advantage of latecomer firm. Asia Pacific Journal of Management, 19(4), 467-488.

MacDougall, W. (2012). The medical technology industry in Germany. Berlin: German Trade and Invest. 
Morgan, N. A., Kaleka, A., \& Katsikeas, C. S. (2004). Antecedents of export venture performance. Journal of Marketing, (68), 90-108.

Murray, J. Y., Gao, G. Y., \& Kotabe, M. (2011). Market orientation and performance of export ventures: The process through marketing capabilities and competitive advantages. Journal of the Academy of Marketing Science, 39(2), 252-269.

Mitchell, W. J., Shaver, M., \& Yeung, B. (1992). Getting there in a global industry: Impacts on performance of changing international presence. Strategic Management Journal, 13(6), 419-432.

Namiki, N. (1988). Export Strategy for small Business. Journal for Small Business Management, 26(2), 32.

Piaskowsi, D. (2012). The importance of international experience for the international orientation and foreign acquisition decisions. British Journal of Management.

Porter, M. E. (1980). Coalitions and global strategy, competition in global industries. Boston: Harvard Business School Press.

Porter, M. E. (1986). Competitive strategy: Techniques for analyzing industries and competitors. New York: Free Press.

Qian, G., \& Lee, L. (2003). Profitability of SMEs in high-tech industries. Strategic Management Journal, 34(6), 881-887.

Schulz, A., Borghoff, T., Kraus, S. (2009). International Entrepreneurship: Towards a Theory of SME Internationalization. Int. Journal of Business and Economics, 9(1), 9-12.

Shaw, V., \& Darroch, J. (2004). Barriers to internationalization: A study of entrepreneurial new ventures in New Zealand. Journal of International Entrepreneurship, 2, 327-343.

Spectarise, V., \& Fachverband, M. (2010). Medical Technology. Yearly dates as an overview, Berlin.

Souitaris, V. (2001). Strategic influences of technological innovation in Greece. British Journal of Management, 12(2), 131-147.

Souchon, A. L., Diamantopoulos, A., Holzmüller, H. H., Axinn, C. N., Sinkula, J. M., Simmet, H., \& Durden, G. R. (2003). Export information use: A five-country investigation of key determinants. Journal of International Marketing, 11(3), 106-127.

Terziovski, M. (2010). Innovation practice and its performance implications in small and medium enterprises (SMEs) in the manufacturing sector: A resource-based view. Strategic Management Journal, 31(8), 892-902.

Thedosiou, M., \& Katsikeas, E. (2013). The export information system. Journal of International Marketing, 21(3), 72-94.

Tranfield, D., Denyer, D., \& Smart, P. (2003). Towards a methodology for developing evidence-informed management knowledge by means of systematic review. British Journal of Management, 814(3), 207-222.

Vignali, C., Vrontis, D., \& Tihomir, V. T. (2003). Marketing planning: Analysis, tactics and strategy. Italia: Foxwell \& Davies. Vignali, C. (2003). International journal of sales, retail \& marketing. UK: Access Press.

Wheelen, T., \& Hunger, D. (2006). Strategy management and business policy (6th ed.). Pearson Education.

Williamson, P. J. (1990). Winning the export war: British, Japanese and west German exporters' strategy compared. British Journal of Management, 1(4), 215-230.

Wintermantel, E. (Hrsg.). (2009). Medizintechnik. Life Science Engineering. Interdisziplinarität, Biokompatibilität, Technologien, Implantate, Diagnostik, Werkstoffe.

Whittington, R. (2001). Four perspectives of strategy: What is strategy and does it matter? London: Thomson Learning.

Wirtschaftslexikon, G. (2012), 14. Auflage, Band 4, Gabler-Verlag, Wiesbaden, 2012. 